\section{Purinas y ácido úrico en pre-eclampsia: interacciones fisiopatológicas y proyecciones en investigación}

\author{
CARLOS ESCUDERO ${ }^{1}$, PATRICIO BERTOGLIA ${ }^{2,3}$, \\ FELIPE MUÑOZ ${ }^{2,3}$, JAMES M. ROBERTS ${ }^{4}$
}

\section{Uric acid and purine plasma levels as plausible markers for placental dysfunction in pre-eclampsia}

Uric acid is the final metabolite of purine break down, such as ATP, ADP, AMP, adenosine, inosine and hypoxanthine. The metabolite has been used broadly as a renal failure marker, as well as a risk factor for maternal and neonatal morbidity during pre-eclamptic pregnancies. High purine levels are observed in pre-eclamptic pregnancies, but the sources of these purines are unknown. However, there is evidence that pre-eclampsia (mainly severe pre-eclampsia) is associated with an increased release of cellular fragments (or microparticles) from the placenta to the maternal circulation. These in fact could be the substrate for purine metabolism. Considering this background, we propose that purines and uric acid are part of the same physiopathological phenomenon in pre-eclampsia (i.e., placental dysfunction) and could become biomarkers for placental dysfunction and postnatal adverse events.

(Rev Med Chile 2013; 141: 895-902).

Key words: Pre-eclampsia; Purines; Uric acid.

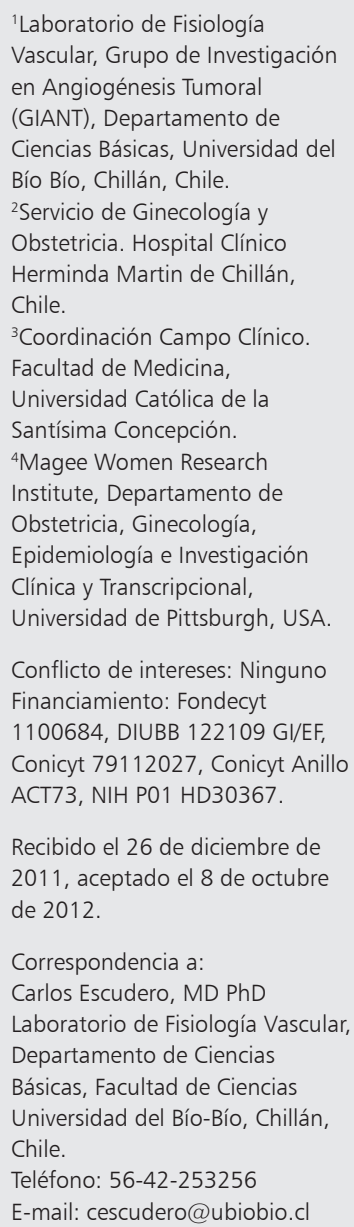

$\mathrm{E}$ 1 ácido úrico, producto final del metabolismo de las purinas, es utilizado como marcador de daño renal y factor de riesgo de morbilidad materna y neonatal en embarazos con pre-eclampsia ${ }^{1-3}$. Así, las mujeres hipertensas e hiperuricémicas tienen mayor riesgo de parto pretermino, retardo de crecimiento intrauterino (RCIU) y pre-eclampsia de origen temprano ( $<34$ semanas), que aquellas mujeres con embarazos normales o mujeres pre-eclámpticas sin hiperuricemia ${ }^{3,4}$. Conjuntamente, una serie de

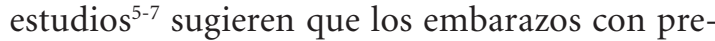
eclampsia cursan con altos niveles de purinas (i.e., ATP, ADP, AMP, adenosina). Las causas o efectos de este aumento en el metabolismo de las purinas hasta ácido úrico no se conocen; sin embargo, dado que pre-eclampsia (principalmente de origen temprano) se asocia a un aumento en la liberación de restos celulares hacia la circulación materna, es posible que estos constituyan el principal sustrato para el metabolismo de las purinas, y finalmente formación de ácido úrico ${ }^{8}$. Por ello, el aumento de ácido úrico y purinas en embarazos con pre-eclampsia no sólo obedecería a la alteración de la función renal, sino que sería un marcador de disfunción placentaria. El objetivo de este trabajo es contribuir en el análisis del rol de las purinas y el ácido úrico en la fisiopatología de pre-eclampsia y con ello replantear su potencial rol predictivo en pre-eclampsia y enfermedades cardiovasculares. Es necesario indicar que este es un análisis de la literatura disponible en el cual nos permitimos especular sobre estas posibles conexiones. 


\section{Pre-eclampsia y disfunción placentaria}

La pre-eclampsia afecta a $\sim 7 \%$ de los embarazos y es la principal causa de morbi-mortalidad materna y fetal ${ }^{9}$. Además, pre-eclampsia de inicio temprano ( $<34$ semanas) está asociada generalmente a mayor riesgo de morbi-mortalidad materna y neonatal que pre-eclampsia de inicio tardío (> 34 semanas $)^{10,11}$.

La fisiopatología de pre-eclampsia indica los siguientes acontecimientos: una reducción inicial en la invasión del trofoblasto hacia los vasos espirales maternos, generaría una deficiente transformación de estos vasos de resistencia en vasos de capacitancia (i.e, con características de vasos venosos). En este escenario, los vasos espirales maternos mantienen su capacidad de contracción, y pueden provocar un flujo intermitente de sangre hacia la placenta asociado a un aumento en la presión de perfusión; lo que generaría a su vez, un continuo estrés de roce sobre las vellosidades placentarias, y fundamentalmente sobre el sincitiotrofoblasto (que está en directo contacto con la circulación materna $)^{12}$. Estos fenómenos desencadenarían daño celular (i.e., necrosis), lo cual generaría el desprendimiento y liberación de fragmentos celulares (micropartículas o nanopartículas) desde la placenta hacia la circulación materna ${ }^{13}$. En su interior ( $y$ en las mismas membranas celulares que los forman) estos fragmentos celulares llevan elementos nocivos para el endotelio materno tales como fosfolípidos modificados, proteínas antiangiogénicas -entre ellas el receptor soluble del factor de crecimiento de endotelio vascular tipo 1 (sVEGFR1 o sFlt-1) o el receptor soluble de endoglina (sEnd)-, radicales libres, purinas, etc. Los "factores" o "moléculas" generadas serían las responsables de provocar una respuesta inflamatoria exacerbada, disfunción endotelial y con ello vasoconstricción (hipertensión) y endoteliosis glomerular (proteinuria) a nivel materno. Al mismo tiempo, estos cambios generarían un círculo vicioso que afectaría continuamente el flujo sanguíneo placentario, y con ello, nuevamente comprometerían la función endotelial materna. A su vez, la disfunción endotelial materna, provocaría similar alteración a nivel fetal; lo cual se traduciría en mayor riesgo cardiovascular luego del embarazo tanto en la madre como en su descendencia $^{12,14}$.

\section{Ácido úrico y pre-eclampsia}

El ácido úrico es el metabolito final de la degradación de las purinas ${ }^{8}$. En el embarazo normal, los niveles de ácido úrico son dinámicos, caracterizándose por una reducción inicial en los primeros meses de embarazo, seguido de un aumento continuo en el tercer trimestre hasta el parto, y una posterior reducción hasta alcanzar una concentración similar a antes del embarazo ${ }^{5}$. Para determinar la presencia de hiperuricemia en mujeres embarazadas se consideran como puntos de corte, un nivel de ácido úrico de $5,8 \mathrm{mg} / \mathrm{dL}$ o $350 \mu \mathrm{mol} / \mathrm{L}^{5}$, o la elevación de al menos un desvío estándar por sobre la media, considerando la edad gestacional ${ }^{1}$.

En pre-eclampsia, Redman y cols. ${ }^{15}$ mostraron que los niveles altos de ácido úrico podrían predecir eventos fetales adversos en mujeres con hipertensión del embarazo. Posterior a ello, varios estudios resumidos en revisiones recientes ${ }^{5,16-18}$, confirman un elevado riesgo ( $\sim 2$ veces) de presentar resultados perinatales adversos, tanto en la madre como en el recién nacido en mujeres hipertensas con hiperuricemia. Concretamente, en relación a los resultados adversos en el recién nacido, Roberts y cols. ${ }^{3}$ mostraron que las mujeres hipertensas e hiperuricémicas, tienen mayor riesgo de diagnóstico de bajo peso para la edad gestacional ( $\sim 3$ veces) o parto $<37$ semanas $(\sim 10$ veces). Evidencia confirmada por otro grupo en Australia ${ }^{19}$. En nuestro hospital, encontramos que el nivel de ácido úrico en el tercer trimestre se correlacionó negativamente con el peso y la talla de los recién nacidos en forma independiente de la edad gestacional de parto en mujeres hipertensas ${ }^{4}$.

Además, un estudio prospectivo ${ }^{20}$ que incluyó un grupo de embarazadas a partir de las 4 semanas de gestación confirmó que la hiperuricemia en embarazos pre-eclámpticos está asociada a parto pretérmino y bajo peso para la edad gestacional. Es interesante resaltar que al ajustar el nivel de ácido úrico para la creatinina sérica; la hiperuricemia en mujeres con hipertensión estaba relacionada con una alteración renal, únicamente al final del embarazo $^{20}$. Estos resultados sugieren que los cambios en el primer trimestre estarían asociados a una mayor generación de ácido úrico en lugar de disminución en la función renal. En forma complementaria, otro estudio ${ }^{21}$ encontró que el aumento de ácido úrico en mujeres con pre- 
eclampsia en el tercer trimestre de gestación fue $\sim 60 \%$, mientras que la relación entre ácido úrico/ creatinina disminuyó en $\sim 17 \%$, lo cual sugiere que inclusive al final del embarazo existe un aumento de ácido úrico no asociado a causa renal ${ }^{2}$.

En otro estudio de seguimiento ${ }^{1}$, que incluyó 1.500 mujeres embarazadas en el primer trimestre ( $~ 9$ semanas), se encontró que el mayor número de partos pretérmino o de pequeños para la edad gestacional estuvieron en el grupo de embarazadas con diagnóstico de pre-eclampsia (hipertensión + proteinuria) o hipertensión + hiperuricemia, quienes además mostraron altos niveles de ácido úrico en el primer trimestre. Adicionalmente, si consideramos el grupo de pre-eclampsia o preeclampsia asociada a hiperuricemia como los casos más severos; la hiperuricemia del primer trimestre, constituye una herramienta útil para identificar a mujeres con $\sim 3$ veces más riesgo de presentar dichas condiciones. En consecuencia, la hiperuricemia en el primer trimestre es un biomarcador que permite identificar mujeres y fetos en riesgo de presentar eventos adversos perinatales.

Sin embargo, estas evidencias plantean varias incógnitas que van más allá del rol predictivo del ácido úrico, tales como: ¿Es posible que la elevación del nivel de ácido úrico ocurra antes del embarazo? Si fuera así, ¿es posible que exista una alteración sistémica o renal subclínica que afecte el metabolismo o eliminación de las purinas y que se manifieste en el embarazo? O por otro lado, ¿cuál sería el origen endógeno de generación de purinas durante el segundo trimestre en embarazo con hipertensión? Además, ¿cuál sería el impacto de estos cambios en la progenie? En relación a esta última pregunta, se ha encontrado que los niveles de ácido úrico en cordón umbilical se correlacionan muy bien $(r=0,70, p<0,001)$ con los niveles encontrados en la madre, tanto en embarazos normales como en pre-eclampsia ${ }^{22}$, y además se conoce que los niños nacidos de bajo peso para la edad gestacional o prematuros (complicaciones frecuentes de embarazos con pre-eclampsia) muestran niveles altos de ácido úrico ${ }^{23}$. Asimismo, los niños con elevación de la presión arterial presentan niveles altos de ácido úrico comparado con niños normotensos ${ }^{23}$, lo cual estaría asociado a un elevado riesgo ( $\sim 2$ veces) de hipertensión en la adolescencia ${ }^{24}$. Para complementar, en adultos y sobre todo en mujeres, se ha reportado que la elevación en los niveles de ácido úrico constituye un factor de riesgo independiente para hipertensión ${ }^{25}$ o muerte por enfermedad coronaria ${ }^{26}$. Cabe resaltar, que no se ha estudiado la relación entre el ácido úrico al nacimiento y el riesgo de hipertensión del embarazo en la vida adulta. Pero, de acuerdo a lo enunciado es posible suponer un componente hereditario, por tanto, presente inclusive antes del embarazo.

Otro tema a ser analizado, es el origen de la hiperuricemia en embarazos con hipertensión. En ese sentido, se ha reportado que la placenta expresa xantina oxidasa, la enzima encargada de la síntesis de ácido úrico ${ }^{27}$, y que la expresión de esta enzima esta aumentada en placentas de mujeres con pre-eclampsia ${ }^{28}$; sugiriendo que la placenta podría ser el origen del exceso de producción de este metabolito. Además, evidencias indirectas, atribuyen también a la placenta, la generación de ácido úrico en pre-eclampsia. Así, en esta patología se ha mostrado aumento de la actividad de xantina oxidasa en la circulación feto-placentaria ${ }^{29}$; así como de la conversión de xantina reductasa a xantina oxidasa, con la consecuente generación de radical superóxido y peróxido de hidrógeno ${ }^{29-31}$. Además, y más importante para la visión planteada en este trabajo, es el aumento del recambio de células trofoblásticas, cuyos fragmentos pueden alcanzar la circulación materna ${ }^{32}$, y constituir el sustrato para la generación de ácido úrico.

\section{Marcadores de disfunción placentaria ligados a generación de ácido úrico y purinas}

\section{Micropartículas y nanopartículas}

Los fragmentos de sincitiotrofoblasto son liberados desde la placenta hacia la circulación materna, como un mecanismo normal de interacción inmunológica entre la madre y el feto. En embarazos normales este fenómeno inicia con la muerte programada (i.e., apoptosis) del sincitiotrofoblasto y la posterior liberación de estos fragmentos hacia la circulación materna donde alcanza la circulación pulmonar, y son fagocitados por macrófagos alveolares ${ }^{13,33}$. Adicionalmente, en pre-eclampsia de inicio temprano $(<34$ semanas $)$ existe un aumento ( $\sim 2$ veces) de micropartículas de sinciotrofoblasto (STBM, por sus siglas en inglés) en comparación con RCIU o embarazos normales $^{32}$. Además, en mujeres con pre-eclampsia de inicio tardío (> 34 semanas) hubo una tendencia 
al aumento de STBM pero no alcanzó diferencias significativas ${ }^{32}$. Estos hallazgos, son congruente con lo encontrado en relación al nivel de ácido úrico en estudios de seguimiento ${ }^{1,3}$, sugiriendo la interacción de ácido úrico con estos fragmentos celulares. Sin embargo, la asociación entre STBM y ácido úrico en embarazos con pre-eclampsia no ha sido investigada; aunque es importante resaltar que el nivel de STBM aumenta progresivamente según la edad gestacional, siendo consistentemente detectables a partir del segundo trimestre ( 15 a 25 semanas de gestación $)^{34}$, coincidiendo también con lo reportado en el nivel de ácido úrico en embarazos normales ${ }^{5}$ o patológicos ${ }^{1,3}$.

\section{Niveles de ADN libre de origen fetal (ffDNA)}

Varios grupos ${ }^{35,36}$ han mostrado elevados niveles de ffDNA previo al inicio de la pre-eclampsia. Levine y cols. ${ }^{35}$ en un grupo de 120 mujeres que desarrollaron pre-eclampsia, mostraron que los niveles de ffDNA aumentaron $\sim 4$ veces en comparación con las mujeres control, a partir de las 17 semanas de gestación. Adicionalmente, mostraron que este aumento es bifásico, con una elevación inicial entre las 17 y 28 semanas; y otra, 3 semanas antes del inicio de los síntomas clínicos. Los autores no encontraron evidencia de inflamación provocada a partir de esta liberación de ffDNA y sugirieron un daño placentario como el generador de este ffDNA. Sumado a esta evidencia, otro estudio ${ }^{37}$ mostró que los niveles de ffDNA se correlacionaron con la alteración de la perfusión placentaria (i.e., aumento del índice de pulsaciones en la arteria uterina) y la severidad de la enfermedad. Estos resultados refuerzan el concepto de que el daño placentario seria el origen del ffDNA en la circulación materna, y es posible que estos niveles permitan la identificación del grupo de embarazadas pre-eclámpticas con mayor riesgo perinatal ${ }^{38}$. En ese sentido, Illanes y cols. ${ }^{36}$ mostraron que la elevación de una unidad en los niveles de ffDNA, aumenta en 67\% el riesgo de sufrir pre-eclampsia asociado a RCIU antes de las 35 semanas (i.e., pre-eclampsia severa).

Se ha mostrado también que las micropartículas presentes en mujeres con pre-eclampsia llevan en su interior $\mathrm{ADN}$ fetal ${ }^{39}$, cuyo rol aún no ha sido determinado. Sin embargo, es fácil asumir que estos altos niveles de ADN fetal (libre o asociado a micropartículas) presente en pre-eclampsia deben ser metabolizados por la madre, constituyéndose en el sustrato para la generación de purinas y finalmente ácido úrico ${ }^{31}$.

Aunque existe un sin número de evidencias en la literatura sobre el rol de ácido úrico en mujeres con pre-eclampsia, poca atención se ha dado a moléculas predecesoras dentro de su metabolismo tales como nucleótidos y nucleósidos (Figura 1). Esto refleja la opinión que prevalece en este tema, en donde la hiperuricemia en mujeres con pre-eclampsia se asocia principalmente a una alteración en la secreción antes que a aumento en la síntesis. Sin embargo, creemos que esta visión no es completamente objetiva, ya que deja de lado la posible participación de la placenta en la generación de purinas y ácido úrico. Además, estas moléculas predecesoras por si mismas tienen una gran variedad de efectos biológicos que podrían ser parte de la fisiopatología de pre-eclampsia.

\section{Purinas en la pre-eclampsia}

Las purinas (adenina y guanina) son bases nitrogenadas que constituyen parte de una serie de compuestos activos a nivel celular. Dentro de dichos compuestos, para el caso de la base adenina se incluyen: 1) los nucleótidos(adenina + azúcar + fosfato), cuyos representantes son el adenosin tri, di y monofosfato (ATP, ADP y AMP, respectivamente); y 2) los nucleósidos (adenina + azúcar) cuyo representante es la adenosina, que es constituyente de los nucleótidos, forma parte de las cadenas de ADN y ARN, y además tiene efectos directos de señalización ${ }^{40}$. En la Figura 1 se esquematiza el metabolismo de las purinas hasta la generación de ácido úrico, enfatizando aquellas reportadas como aumentadas en pre-eclampsia ${ }^{41}$ (Figura 1).

En mujeres gestantes, se ha mostrado una elevada concentración plasmática de adenosina respecto a no embarazadas ${ }^{42}$, lo cual ha sido asociado a una elevación en el metabolismo de ATP y degradación de adenosina hasta inosina ${ }^{43}$. Así, el embarazo normal per se, es un estado de mayor metabolismo purinérgico. Por otro lado, varios reportes ${ }^{44,45}$, incluyendo los nuestros ${ }^{6,40}$, muestran elevación en los niveles plasmáticos de adenosina en embarazos con pre-eclampsia en forma dependiente de la severidad ${ }^{44}$. Al igual que el embarazo normal, este fenómeno estaría relacionado con un aumento en el metabolismo de 


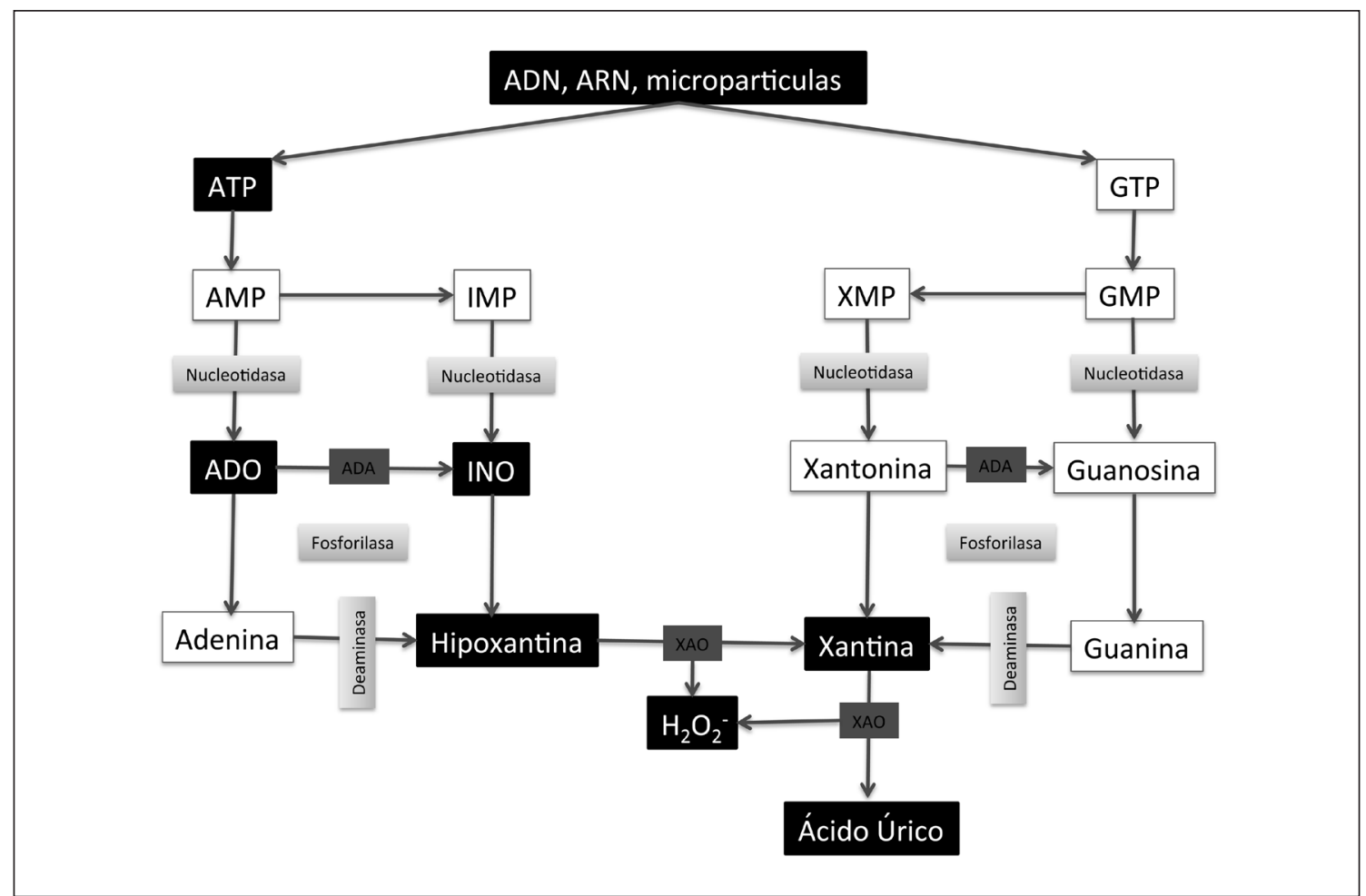

Figura 1. Vía metabólica de producción de ácido úrico. Las purinas son las bases nitrogenadas adenina y guanina. Se muestra la vía metabólica de las purinas hasta la síntesis del metabolito final el ácido úrico. Ácidos nucleicos (ADN, ARN), adenosina y guanosina trifosfato (ATP y GTP); o monofosfato (AMP y GMP, respectivamente); inosina-monofosfato (IMP), adenosina (ADO), inosina (INO); xantina monofosfato (XMP). Las enzimas involucradas son nucleotidasas, adenosina desaminasa (ADA), fosforilasa de nucleosidos (forforilasa) y xantina oxidasa (XAO). Un subproducto de la formación de ácido úrico a través de la xantina oxidasa es el peróxido de hidrógeno $\left(\mathrm{H}_{2} \mathrm{O}_{2}{ }^{-}\right)$. Los cuadros más oscuros representan los componentes de la vía metabólica que han sido estudiados en pre-eclampsia y cuyos niveles o actividad en el casos de las enzimas ha sido reportado como aumentado.

ATP asociado a una reducción en la degradación de adenosina $a^{7,40}$. Las causas y consecuencias de la elevación de purinas en plasma materno durante la pre-eclampsia aún no se conocen. Sin embargo, de acuerdo a lo expuesto, causalmente estarían asociados a los altos niveles de ADN fetal ${ }^{31}$ y STBM. En relación a las consecuencias, se ha mostrado una positiva correlación entre adenosina y ácido úrico en humanos ${ }^{8,45} \mathrm{y}$ además la infusión de ATP resulta en la generación de un modelo similar a pre-eclampsia en ratas ${ }^{46}$.

Otra pregunta es, ¿Cual sería la finalidad biológica del aumento en el nivel de purinas y ácido úrico en embarazos con pre-eclampsia? En ese sentido, si consideramos que el aumento de estos marcadores provendría de la placenta, es posible suponer que la respuesta biológica este encaminada a compensar la reducción del flujo sanguíneo feto-placentario en este tipo de embarazos. ¿Cómo se realizaría? La respuesta es difícil de abordar dado la falta de información; sin embargo, podrían incluir los siguientes mecanismos: 1) Potenciación antioxidante, ya que el ácido úrico es un antioxidante endógeno ${ }^{8}$, y además se ha mostrado que la estimulación de receptores de ATP aumenta la expresión de varias enzimas antioxidantes ${ }^{47}$. Por tanto, es posible que mejore la sobrevida de células endoteliales y con ello el control del tono vascular, el recambio del endotelio disfuncional, y aumento de la formación de nuevos vasos sanguíneos, entre otros posibles efectos; 2) Control del tono vascular, ya que las purinas y el ácido úrico pueden generar cambios en la biodisponibilidad de sustancias vasomoduladoras como óxido nítrico (NO). Este mecanismo sería responsable por ejemplo de disminuir la resistencia en la pared vascular existente 
en vasos placentarios y facilitar y/o redistribuir el flujo sanguíneo en la placenta y 3 ) Aumento de la red vascular en la placenta, ya que se conoce que las purinas aumentan la formación de nuevos vasos sanguíneos (i.e., angiogénesis). Así, a través de este mecanismo se conseguiría aumentar las posibilidades de conducción sanguínea a los lechos en donde se requieran ${ }^{40,48}$. De acuerdo a esta visión integrativa, es probable que el aumento en los niveles plasmáticos de micropartículas, $\mathrm{ADN}$ fetal, purinas y ácido úrico presente en pre-eclampsia, sean parte del mismo fenómeno fisiopatológico; den cuenta de un tipo específico de pre-eclampsia cuya alteración se encuentre fundamentalmente a nivel placentario; $y$ es probable que al menos alguno de ellos, como el ácido úrico, se mantengan posterior al embarazo generando un mayor riesgo cardiovascular tanto en la madre como la progenie.
En conclusión, la hiperucemia en embarazos con hipertensión está asociada a pobres resultados perinatales. Así, la elevación del ácido úrico y purinas en el primer trimestre pudiera ser una herramienta pronostica de fácil determinación que permitiría identificar un grupo de pacientes con pre-eclampsia asociada a daño placentario. Por otro lado, existen muchas preguntas sobre las implicaciones fisiopatológicas en la madre y en feto de la elevación de purinas y ácido úrico, que requieren ser resueltas. La proyección de estas investigaciones podría no sólo permitir un adecuado entendimiento de los fenómenos fisiopatológicas de la disfunción placentaria en embarazos con pre-eclampsia, sino además pueden extenderse hacia la comprensión de cómo un mecanismo inicialmente compensatorio a nivel fetal, podría constituirse en un factor de riesgo a posterior durante la vida adulta (Figura 2).

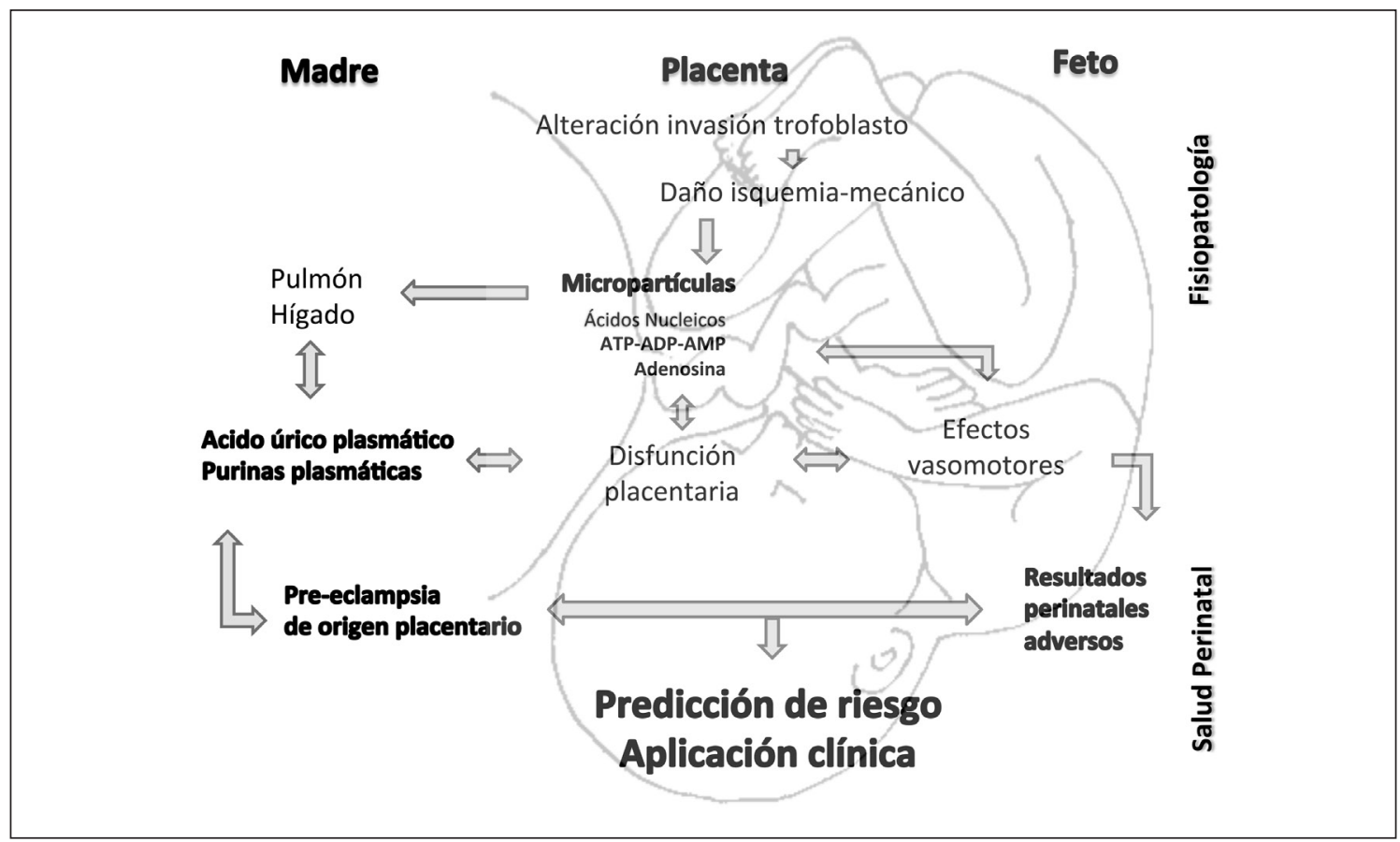

Figura 2. Integración de los niveles de ácido úrico y purinas en el esquema fisiopatológico de embarazos con pre-eclampsia. Se muestra la integración entre madre, placenta y feto. La alteración de la invasión del trofoblasto llevaría a un daño isquémico y estrés de fricción sobre las células placentarias (sincitiotrofoblasto), lo cual desencadenaría la liberación de fragmentos celulares (i.e., micropartículas) hacia la circulación materna. Estas micropartículas llegarían a la circulación materna, y constituirían marcadores de daño placentario. Paralelamente, los fragmentos celulares serían metabolizados en el pulmón e hígado, formando otros compuestos como las purinas (ATP, ADP, AMP, adenosina, hipoxantina, entre otras). Adicionalmente, esto podría constituirse en un círculo vicioso en donde los efectos vasculares que tendrían todos estos compuestos, y en particular el ácido úrico y las purinas, podrían profundizar el daño endotelial materno y placentario. En consecuencia, la aplicabilidad clínica de ácido úrico y las purinas predecesoras a este metabolito, sería una herramienta clínica de fácil acceso, que permitiría caracterizar bioquímicamente un tipo de pre-eclampsia asociado a daño placentario. 
Agradecimientos: Este trabajo fue financiado por los proyectos Fondecyt 1100684, DIUBB 122109 GI/EF, Conicyt 79112027, Conicyt Anillo ACT73. El aporte del Dr. Roberts fue parcialmente financiado por NIH P01 HD30367. Al Laboratorio de Fisiología Vascular y Grupo de Investigación en Angiogénesis Tumoral (GIANT) del Departamento de Ciencias Básicas de la Universidad del Bío Bío y al Servicio de Ginecología y Obstetricia del Hospital Herminda Martin de Chillán, Chile; por su continuo soporte en la realización de los estudios detallados en este trabajo.

\section{Referencias}

1. Laughon SK, Catov J, Powers RW, Roberts JM, Gandley RE. First trimester uric acid and adverse pregnancy outcomes. Am J Hypertens 2011; 24 (4): 489-95. PMCID: 3062659.

2. Bainbridge SA, Roberts JM. Uric acid as a pathogenic factor in preeclampsia. Placenta 2008; 29 Suppl A: S67-72.

3. Roberts JM, Bodnar LM, Lain KY, Hubel CA, Markovic $\mathrm{N}$, Ness RB, et al. Uric acid is as important as proteinuria in identifying fetal risk in women with gestational hypertension. Hypertension 2005; 46 (6): 1263-9.

4. Bertoglia P RA, Navarrete P, Castro L, Acurio J, Escudero C. Resultados clínicos y perinatales de los embarazos con hipertensión arterial en un hospital de referencia de la VIII Región de Chile. Revista Chilena de Obstetricia y Ginecología 2010; 75 (3): 162-71.

5. Koopmans CM, van Pampus MG, Groen H, Aarnoudse JG, van den Berg PP, Mol BW. Accuracy of serum uric acid as a predictive test for maternal complications in pre-eclampsia: bivariate meta-analysis and decision analysis. Eur J Obstet Gynecol Reprod Biol 2009; 146 (1): 8-14.

6. Escudero C, Casanello P, Sobrevia L. Human equilibrative nucleoside transporters 1 and 2 may be differentially modulated by $\mathrm{A} 2 \mathrm{~B}$ adenosine receptors in placenta microvascular endothelial cells from pre-eclampsia. Placenta 2008; 29 (9): 816-25.

7. Malek A, Miller RK, Mattison DR, Ceckler T, Panigel M, di Sant'Agnese PA, et al. Continuous measurement of ATP by 31P-NMR in term human dually perfused placenta in vitro: response to ischemia. J Appl Physiol 1995; 78 (5): 1778-86.

8. Martin AC, Brown MA. Could uric acid have a pathogenic role in pre-eclampsia? Nat Rev Nephrol 2010; 6 (12): 744-8.

9. Young BC, Levine RJ, Karumanchi SA. Pathogenesis of preeclampsia. Annu Rev Pathol 2010; 5: 173-92.

10. von Dadelszen P, Magee LA, Roberts JM. Subclassifica- tion of preeclampsia. Hypertens Pregnancy 2003; 22 (2): 143-8.

11. Geller SE, Ahmed S, Brown ML, Cox SM, Rosenberg D, Kilpatrick SJ. International Classification of Diseases-9th revision coding for preeclampsia: how accurate is it? Am J Obstet Gynecol 2004; 190 (6): 1629-33; discussion 33-4.

12. Burton GJ, Woods AW, Jauniaux E, Kingdom JC. Rheological and physiological consequences of conversion of the maternal spiral arteries for uteroplacental blood flow during human pregnancy. Placenta 2009; 30 (6): 473-82. PMCID: 2697319.

13. Burton GJ, Jones CJ. Syncytial knots, sprouts, apoptosis, and trophoblast deportation from the human placenta. Taiwan J Obstet Gynecol 2009; 48 (1): 28-37.

14. Roberts JM, Rajakumar A. Preeclampsia and soluble fms-like tyrosine kinase 1. J Clin Endocrinol Metab 2009; 94 (7): 2252-4. PMCID: 2708948.

15. Redman CW, Beilin LJ, Bonnar J, Wilkinson RH. Plasma-urate measurements in predicting fetal death in hypertensive pregnancy. Lancet 1976; 1 (7974): 1370-3.

16. Cnossen JS, de Ruyter-Hanhijarvi H, van der Post JA, Mol BW, Khan KS, ter Riet G. Accuracy of serum uric acid determination in predicting pre-eclampsia: a systematic review. Acta Obstet Gynecol Scand 2006; 85 (5): 519-25.

17. Thangaratinam S, Ismail KM, Sharp S, Coomarasamy A, Khan KS. Accuracy of serum uric acid in predicting complications of pre-eclampsia: a systematic review. Bjog 2006; 113 (4): 369-78.

18. Conde-Agudelo A, Villar J, Lindheimer M. World Health Organization systematic review of screening tests for preeclampsia. Obstet Gynecol 2004; 104 (6): 1367-91.

19. Hawkins TL, Roberts JM, Mangos GJ, Davis GK, Roberts LM, Brown MA. Plasma uric acid remains a marker of poor outcome in hypertensive pregnancy: a retrospective cohort study. Bjog 2012; 119 (4): 484-92.

20. Powers RW, Bodnar LM, Ness RB, Cooper KM, Gallaher MJ, Frank MP, et al. Uric acid concentrations in early pregnancy among preeclamptic women with gestational hyperuricemia at delivery. Am J Obstet Gynecol 2006; 194 (1): 160

21. Hayashi M, Ueda Y, Hoshimoto K, Ota Y, Fukasawa I, Sumori K, et al. Changes in urinary excretion of six biochemical parameters in normotensive pregnancy and preeclampsia. Am J Kidney Dis 2002; 39 (2): 392-400.

22. Catarino C, Santos-Silva A, Belo L, Rocha-Pereira P, Rocha S, Patricio B, et al. Inflammatory Disturbances in Preeclampsia: Relationship between Maternal and Umbilical Cord Blood. J Pregnancy 2012; 2012: 684384. PMCID: 3366239.

23. Park B, Park E, Cho SJ, Kim Y, Lee H, Min J, et al. The association between fetal and postnatal growth status 
and serum levels of uric acid in children at 3 years of age. Am J Hypertens 2009; 22 (4): 403-8.

24. Loeffler LF, Navas-Acien A, Brady TM, Miller ER, 3rd, Fadrowski JJ. Uric acid level and elevated blood pressure in US adolescents: National Health and Nutrition Examination Survey, 1999-2006. Hypertension. 2012; 59 (4): 811-7.

25. Grayson PC, Kim SY, LaValley M, Choi HK. Hyperuricemia and incident hypertension: a systematic review and meta-analysis. Arthritis Care Res (Hoboken) 2011; 63 (1): 102-10. PMCID: 3016454.

26. Kim SY, Guevara JP, Kim KM, Choi HK, Heitjan DF, Albert DA. Hyperuricemia and coronary heart disease: a systematic review and meta-analysis. Arthritis Care Res (Hoboken) 2010; 62 (2): 170-80. PMCID: 3156692.

27. Many A, Westerhausen-Larson A, Kanbour-Shakir A, Roberts JM. Xanthine oxidase/dehydrogenase is present in human placenta. Placenta 1996; 17 (5-6): 361-5.

28. Many A, Hubel CA, Fisher SJ, Roberts JM, Zhou Y. Invasive cytotrophoblasts manifest evidence of oxidative stress in preeclampsia. Am J Pathol 2000; 156 (1): 32131. PMCID: 1868629.

29. Karabulut AB, Kafkasli A, Burak F, Gozukara EM. Maternal and fetal plasma adenosine deaminase, xanthine oxidase and malondialdehyde levels in pre-eclampsia. Cell Biochem Funct 2005; 23 (4): 279-83.

30. Many A, Hubel CA, Roberts JM. Hyperuricemia and xanthine oxidase in preeclampsia, revisited. Am J Obstet Gynecol 1996; 174 (1 Pt 1): 288-91.

31. McMaster-Fay R. Pre-eclampsia e a disease of oxidative stress resulting from the catabolism of DNA (primarily fetal) to uric acid by xanthine oxidase in the maternal liver: A hypothesis. Bioscience Hypotheses 2008; 1: 3543.

32. Goswami D, Tannetta DS, Magee LA, Fuchisawa A, Redman CW, Sargent IL, et al. Excess syncytiotrophoblast microparticle shedding is a feature of early-onset preeclampsia, but not normotensive intrauterine growth restriction. Placenta 2006; 27 (1): 56-61.

33. Chamley LW, Chen Q, Ding J, Stone PR, Abumaree M. Trophoblast deportation: just a waste disposal system or antigen sharing? J Reprod Immunol 2011; 88 (2): 99-105.

34. Germain SJ, Sacks GP, Sooranna SR, Sargent IL, Redman CW. Systemic inflammatory priming in normal pregnancy and preeclampsia: the role of circulating syncytiotrophoblast microparticles. J Immunol 2007; 178 (9): 5949-56.

35. Levine RJ, Qian C, Leshane ES, Yu KF, England LJ, Schisterman EF, et al. Two-stage elevation of cell-free fetal DNA in maternal sera before onset of preeclampsia. Am J Obstet Gynecol 2004; 190 (3): 707-13.

36. Illanes S, Parra M, Serra R, Pino K, Figueroa-Diesel H,
Romero C, et al. Increased free fetal DNA levels in early pregnancy plasma of women who subsequently develop preeclampsia and intrauterine growth restriction. Prenat Diagn 2009; 29 (12): 1118-22.

37. Sifakis S, Zaravinos A, Maiz N, Spandidos DA, Nicolaides KH. First-trimester maternal plasma cell-free fetal DNA and preeclampsia. Am J Obstet Gynecol 2009; 201 (5): 472 e1-7.

38. Tjoa ML, Cindrova-Davies T, Spasic-Boskovic O, Bianchi DW, Burton GJ. Trophoblastic oxidative stress and the release of cell-free feto-placental DNA. Am J Pathol 2006; 169 (2): 400-4. PMCID: 1698796.

39. Orozco AF, Jorgez CJ, Ramos-Pérez WD, Popek EJ, Yu $\mathrm{X}$, Kozinetz CA, et al. Placental release of distinct DNAassociated micro-particles into maternal circulation: reflective of gestation time and preeclampsia. Placenta 2009; 30 (10): 891-7. PMCID: 2758063.

40. Escudero C, Puebla C, Westermeier F, Sobrevia L. Potential cell signalling mechanisms involved in differential placental angiogenesis in mild and severe preeclampsia. Curr Vasc Pharmacol 2009; 7 (4): 475-85.

41. Fausther M, Sevigny J. Extracellular nucleosides and nucleotides regulate liver functions via a complex system of membrane proteins. C R Biol 2011; 334 (2): 100-17.

42. Yoneyama Y, Sawa R, Suzuki S, Ishino H, Miura A, Kuwabara Y, et al. Regulation of plasma adenosine levels in normal pregnancy. Gynecol Obstet Invest 2002; 53 (2): 71-4.

43. Yoneyama Y, Suzuki S, Sawa R, Otsubo Y, Miura A, Kuwabara Y, et al. Serum adenosine deaminase activity and its isoenzyme pattern in women with normal pregnancies. Arch Gynecol Obstet 2003; 267 (4): 205-7.

44. Yoneyama Y, Suzuki S, Sawa R, Yoneyama K, Power GG, Araki T. Increased plasma adenosine concentrations and the severity of preeclampsia. Obstet Gynecol 2002; 100 (6): 1266-70.

45. Suzuki S, Yoneyama Y, Sawa R, Otsubo Y, Takeuchi T, Araki T. Relation between serum uric acid and plasma adenosine levels in women with preeclampsia. Gynecol Obstet Invest 2001; 51 (3): 169-72.

46. Faas MM, van der Schaaf G, Borghuis T, Jongman RM, van Pampus MG, de Vos P, et al. Extracellular ATP induces albuminuria in pregnant rats. Nephrol Dial Transplant 2010; 25 (8): 2468-78.

47. Satoh E, Tsukimoto M, Kojima S. Involvement of P2Y receptors in the protective effect of ATP towards the cell damage in HaCaT cells exposed to $\mathrm{H}$ (2) O (2). J Toxicol Sci 2011; 36 (6): 741-50.

48. Ryzhov S, McCaleb JL, Goldstein AE, Biaggioni I, Feoktistov I. Role of adenosine receptors in the regulation of angiogenic factors and neovascularization in hypoxia. J Pharmacol Exp Ther 2007; 320 (2): 565-72. 